\title{
Optical and mechanical properties of diamond like carbon films deposited by microwave ECR plasma CVD
}

\author{
S B SINGH, M PANDEY ${ }^{\dagger}$, N CHAND, A BISWAS ${ }^{\dagger \dagger}$, D BHATTACHARYA ${ }^{\dagger \dagger}$, S DASH \\ A K TYAGI ${ }^{\#}$, R M DEY ${ }^{\S}, S$ K KULKARNI ${ }^{\S}$ and D S PATIL* \\ Laser and Plasma Technology Division, ${ }^{\dagger}$ High Pressure Physics Division, ${ }^{\dagger}$ Spectroscopy Division, \\ Bhabha Atomic Research Centre, Mumbai 400 085, India \\ \#Materials Science Division, Indira Gandhi Centre for Atomic Research, Kalpakkam 603 102, India \\ ${ }^{\S}$ Department of Physics, University of Pune, Pune 411 007, India
}

MS received 11 January 2008; revised 12 February 2008

\begin{abstract}
Diamond like carbon (DLC) films were deposited on Si (111) substrates by microwave electron cyclotron resonance (ECR) plasma chemical vapour deposition (CVD) process using plasma of argon and methane gases. During deposition, a d.c. self-bias was applied to the substrates by application of $13.56 \mathrm{MHz} \mathrm{rf}$ power. DLC films deposited at three different bias voltages $(-60 \mathrm{~V},-100 \mathrm{~V}$ and $-150 \mathrm{~V})$ were characterized by FTIR, Raman spectroscopy and spectroscopic ellipsometry to study the variation in the bonding and optical properties of the deposited coatings with process parameters. The mechanical properties such as hardness and elastic modulus were measured by load depth sensing indentation technique. The DLC film deposited at $-100 \mathrm{~V}$ bias exhibit high hardness $(\sim 19 \mathrm{GPa})$, high elastic modulus $(\sim 160 \mathrm{GPa})$ and high refractive index $(\sim 2 \cdot 16-2 \cdot 26)$ as compared to films deposited at $-60 \mathrm{~V}$ and $-150 \mathrm{~V}$ substrate bias. This study clearly shows the significance of substrate bias in controlling the optical and mechanical properties of DLC films.
\end{abstract}

Keywords. Diamond like carbon; chemical vapour deposition; mechanical properties; Raman spectroscopy.

\section{Introduction}

Diamond like carbon (DLC) films are being widely studied due to their outstanding properties such as high hardness, wear resistance, low friction coefficient, high electrical resistance, chemical inertness and optical transparency in the infrared region (Groning et al 1997; Sanchez et al 2000; Cicala et al 2004). These films are promising as coatings on tools used in applications that require low friction and high wear resistance and also for photoluminescence and field emission devices. These films can be deposited at room temperature by various physical and chemical vapour deposition (PVD and CVD) methods such as pulsed laser deposition, filtered cathodic vacuum arc deposition and microwave and radio frequency plasma assisted deposition (Lossy et al 1995; Kautek et al 1996; Musil 1996). Microwave ECR plasma CVD process has inherent advantages due to high degree of ionization of the precursor gases, high density of reactive species and low pressure operation. This results in high growth rates, efficient gas utilization and uniformity in deposition. Further due to the fact that substrates can be independently biased, it is possible to control the flux and energy of ions im-

\footnotetext{
*Author for correspondence (dspatil@barc.gov.in)
}

pinging on the substrate surface. This is actually regarded as one of the most important process parameters during DLC deposition (Matsuo and Kiuchi 1983; Grill 1993). The objective of the present study is to deposit DLC coatings on silicon (111) substrates under the influence of different d.c. self bias (developed with the application of RF power to the substrates) and to investigate the effect of this substrate bias level on the structural, optical and mechanical properties of the deposited films.

\section{Experimental}

The DLC films were deposited on the polished, $p$-type silicon (111) substrates using a $2.45 \mathrm{GHz}, 1.5 \mathrm{~kW}$, microwave ECR plasma CVD facility set up in our laboratory. Figure 1 shows the schematics of the experimental system. The ECR plasma is generated in a chamber that is surrounded by two water-cooled electromagnet coils that are powered independently by constant current regulated power supplies. The distance between the coils can be adjusted to generate a desired magnetic field profile in the plasma generation chamber. The current in the top and bottom coil was set at $130 \mathrm{~A}$ and $170 \mathrm{~A}$, respectively that generates a magnetic field profile having two ECR zones (one near the quartz isolation window and other near the exit of the ECR plasma generation chamber). This magnetic 
field configuration acts as a magnetic field mirror for electrons in ECR plasma source. The microwave power absorption in the ECR zone is associated with the heating of electron that bounces between the two mirror ends of the ECR zones. This results in increase in the electron energy/temperature that leads to further ionization resulting in high density of electrons for efficient decomposition of the hydrocarbon precursors during deposition. The ECR zone near the quartz window can further be shifted to the quartz window (by tuning the magnetic field profile) for creating energetic ions when required for cleaning of the window. This periodic cleaning of the window is required, as during deposition a carbon film is deposited on the quartz window that reduces the microwave transmission. The microwave hardware consists of a $2.45 \mathrm{GHz}$ magnetron capable of delivering a microwave power of up to $1.5 \mathrm{~kW}$. Microwaves are launched in the wave-guide as $\mathrm{TE}_{10}$ waves. The other components in the microwave transmission line are a three-port circulator with a water cooled dummy load, cross coupler that extracts a signal of the microwave power (forward and reflected) with power indicating meters, three stub tuner, a microwave mode converter $\mathrm{TE}_{10}$ to $\mathrm{TM}_{01}$ and a sliding short circuit. Microwaves enter the ECR plasma generation chamber as $\mathrm{TM}_{01}$ waves. The quartz isolation window separates a plasma generation chamber and the microwave hardware. The divergent magnetic field near the exit of the plasma generation chamber helps in generating large volume plasma in the processing chamber where the substrate is located. The substrate stage is isolated from the grounded chamber walls and is coupled to a $13.56 \mathrm{MHz}, 300 \mathrm{~W}$ rf power generator through an impedance matching unit built in our laboratory.

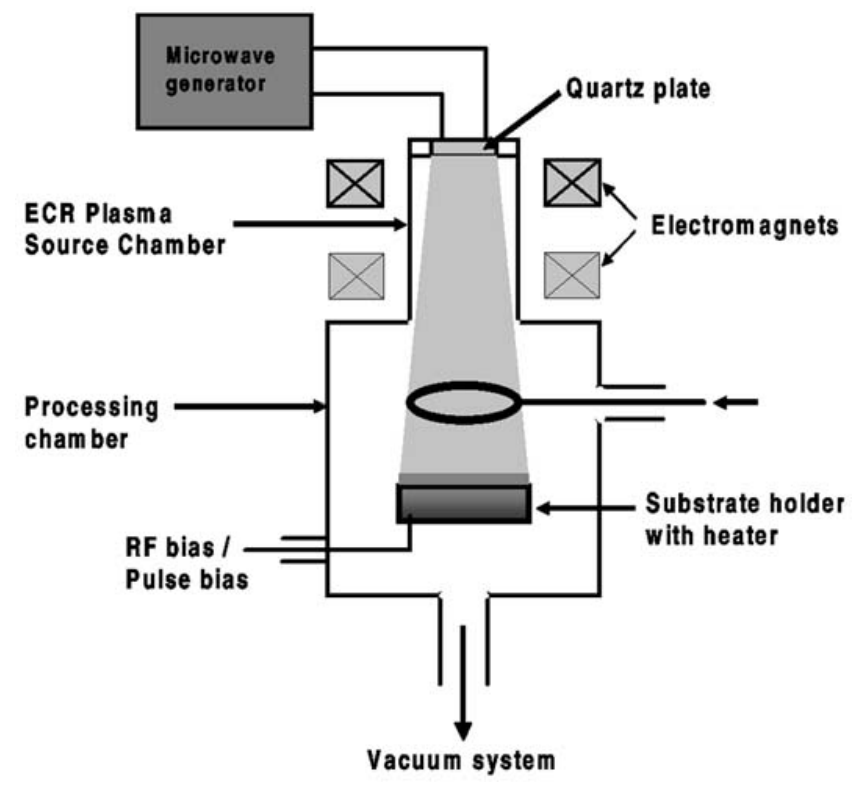

Figure 1. Schematic of the experimental set up of microwave ECR plasma system.
Prior to deposition, Si (111) substrates were ultrasonically cleaned in isopropyl alcohol and kept on a RF electrode. The system was first evacuated to an initial pressure of $1.5 \times 10^{-6}$ mbar using a turbo molecular pump backed by a rotary pump. After stabilization of the plasma of argon gas, substrates were sputter cleaned to remove the residual contaminant impurities and oxide from the surface by application of RF self bias of $-100 \mathrm{~V}$ for $10-15 \mathrm{~min}$. Plasma density measurements near the substrate (by Langmuir probe inserted in the plasma) was found to be $1 \cdot 1-$ $1.4 \times 10^{10} / \mathrm{cm}^{3}$, and also indicated a fairly uniform plasma in the centre of the chamber over an area of $\sim 20 \mathrm{~cm}$ diameter. Methane as a reactant gas was then introduced into the chamber via a gas shower ring positioned $50 \mathrm{~mm}$ above the substrate. The final operating pressure was $5.5 \times 10^{-4}$ mbar. The depositions were carried out at three levels of substrate bias $(-60 \mathrm{~V},-100 \mathrm{~V}$ and $-150 \mathrm{~V})$ for a time duration of $45 \mathrm{~min}-1 \mathrm{~h}$.

Deposited coatings were characterized using a CCD based Raman spectrometer having argon ion laser of excitation wavelength, $532 \mathrm{~nm}$. The infrared spectra of the coatings were recorded in the range $400-4000 \mathrm{~cm}^{-1}$ using a Bomem FTIR with a resolution of $\sim 4 \mathrm{~cm}^{-1}$. Ellipsometric measurements were carried out with a phase modulated spectroscopic unit (model UVSEL ${ }^{\mathrm{TM}} 460$ ISA JOBIN-YVON, SPEX) in the range $350-1200 \mathrm{~nm}$. The mechanical properties (hardness and Young's modulus) of the films were measured using a nanoindenter (CSM Instruments). Berkovich three-sided pyramidal diamond indenter with a nominal angle equal to $65.3^{\circ}$ was used for these measurements. All tests were performed in clean environment at ambient temperature.

\section{Results and discussion}

The DLC films deposited by microwave ECR plasma CVD process were visually smooth and flat. A typical SEM image taken on a film deposited at $-150 \mathrm{~V}$ bias is shown in figure 2. For all films no visible grain features and

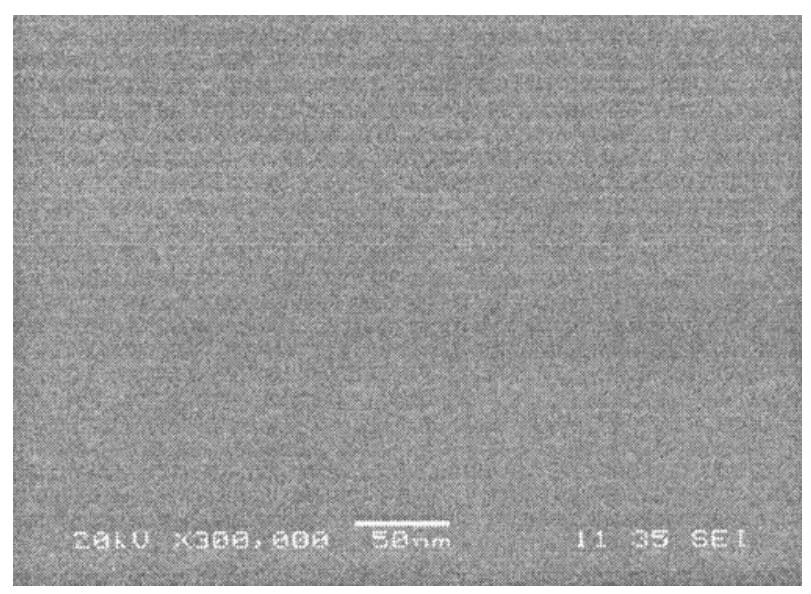

Figure 2. SEM image on film deposited at $-150 \mathrm{~V}$ bias. 
pores could be observed under SEM. The coatings were scratch proof and strongly adherent to substrates. The electrical resistivity of the deposited films was $>200 \mathrm{M} \Omega$.

The thickness of the deposited films as measured by ellipsometry were $0 \cdot 315 \mu \mathrm{m}$ ( $-60 \mathrm{~V}$ bias, $1 \mathrm{~h}$ deposition), $0.248 \mu \mathrm{m}(-100 \mathrm{~V}$ bias, $45 \mathrm{~min}$ deposition) and $0.679 \mu \mathrm{m}$ $(-150 \mathrm{~V}$ bias, $1 \mathrm{~h}$ deposition). The increase in the thickness of the coating with bias voltage is attributed to the increase in the number of radicals which participate in the reaction. This results in enhanced ionization and dissociation of precursor gas due to increased electron energy in the plasma with increase in the bias voltage. The films deposited at $-100 \mathrm{~V}$ bias also showed a high residual stress in the coatings, as repeated attempts to deposit coatings thicker than the ones reported failed. Films deposited for longer duration of time $(>45 \mathrm{~min})$ pilled off the substrate base.

A typical loading-unloading curve (for a film deposited at $-100 \mathrm{~V}$ bias) for a final load of $10 \mathrm{mN}$ is shown in figure 3. Hardness and elastic modulus of the films were estimated from these loading-unloading curves using the Oliver and Pharr method of data analysis (Oliver et al 1992). Hardness and elastic modulus of the DLC films were found to be in the range of $\sim 15-19 \mathrm{GPa}$ and $\sim 132$ $160 \mathrm{GPa}$, respectively as shown in figure 4. From this figure it is clear that the film deposited at $-100 \mathrm{~V}$ bias shows maximum hardness and elastic modulus as compared to the films deposited at lower and higher bias voltages, indicating that there is definitely an optimal $\mathrm{rf}$ induced d.c. substrate bias at which one can get hard films. It is mentioned here that though in practice the depth of indentation should not exceed $10 \%$ of the thickness of the actual coatings during measurement of the hardness of the coatings, here the indentation depth is $\sim 210 \mathrm{~nm}$ which is nearly $85 \%$ of the coating thickness. This, therefore, indi-

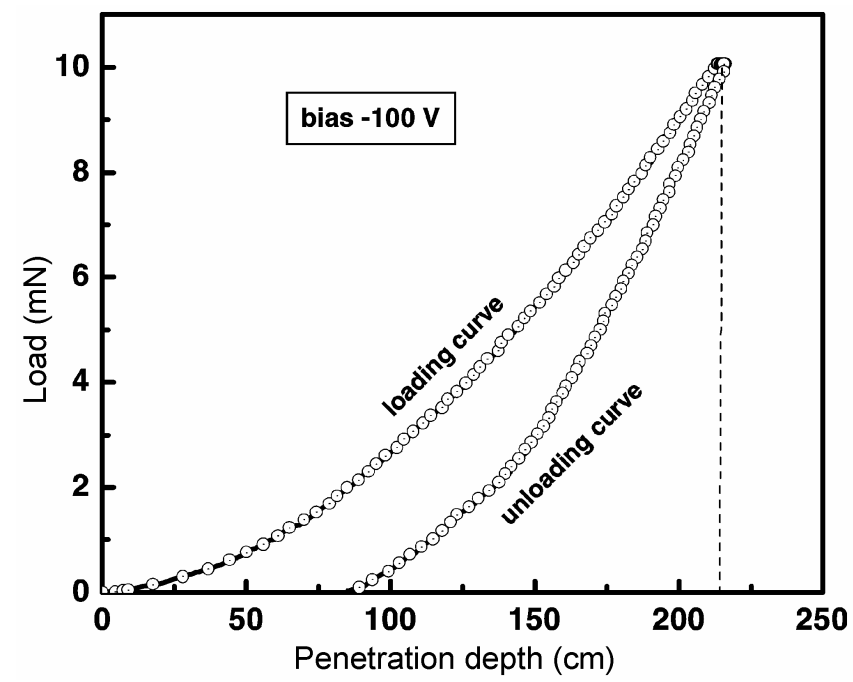

Figure 3. Typical loading-unloading curve of a DLC film deposited at $-100 \mathrm{~V}$ substrate bias. cates that the measured hardness is not the true hardness of the coatings but a composite hardness (i.e. of the film and the substrate together). The true hardness of the coatings is definitely higher than the values reported here. Nevertheless, the observations reported here do represent a trend in the hardness and elastic modulus values with the applied substrate bias. The high value of hardness reported here for a film deposited at $-100 \mathrm{~V}$ bias indicate that this film should have higher values of $s p^{3} / s p^{2}$ ratio of the carbon bonding and also higher density.

Refractive index $(n)$ and extinction coefficient $(k)$ variations with the wavelength for DLC films deposited at different bias voltages $(-60 \mathrm{~V},-100 \mathrm{~V}$ and $-150 \mathrm{~V})$ are shown in figure 5 . The refractive index of these films was found to vary in the range $2 \cdot 26-1 \cdot 82$ with the applied bias as shown in this figure. The refractive index of DLC film deposited at $-100 \mathrm{~V}$ bias is found to show a very low dispersion compared to the films deposited at $-60 \mathrm{~V}$ and $-150 \mathrm{~V}$ bias voltages. The reported value of refractive index for DLC films is in the range $1 \cdot 8-2 \cdot 3$. Dense carbonaceous films have a large refractive index with relatively low dispersion and high amount of hydrogen in the film lowers the refractive index (Sarangi et al 2000). For polymer like hydrocarbon films (deposited at low energy), this is reported to be less than $1 \cdot 8$. From the observed data, inference can be drawn that the DLC film deposited at $-100 \mathrm{~V}$ bias is having high density and is with lesser hydrogen fraction as compared to the films deposited at $-60 \mathrm{~V}$ and $-150 \mathrm{~V}$ bias. The value of the refractive index (n) was found to be maximum $(\sim 2 \cdot 26$ for film deposited at $-100 \mathrm{~V}$ bias) at $400-450 \mathrm{~nm}$, while the extinction coefficient $(k)$ attains a value near to zero for all films at $800 \mathrm{~nm}$ and beyond, indicating that these films are transparent beyond $800 \mathrm{~nm}$. There is a slight but noticeable

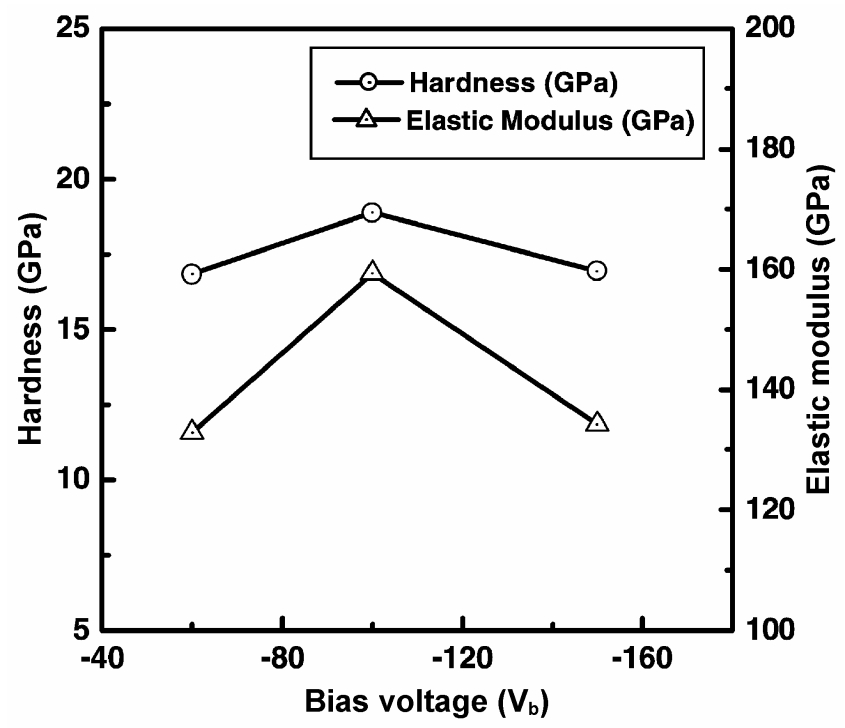

Figure 4. Hardness and Young's modulus of the deposited films as functions of substrate bias. 
Table 1. Peak fitting details of IR absorption spectra.

\begin{tabular}{|c|c|c|c|c|c|c|c|c|c|c|}
\hline \multirow[b]{2}{*}{$\begin{array}{l}\text { Pk } \\
\text { No. }\end{array}$} & \multirow[b]{2}{*}{ Peak assigned } & \multicolumn{3}{|c|}{ (-60 V Bias) } & \multicolumn{3}{|c|}{$(-100$ V Bias $)$} & \multicolumn{3}{|c|}{$(-150$ V Bias $)$} \\
\hline & & $\begin{array}{c}\text { Peak } \\
\text { position } \\
\left(\mathrm{cm}^{-1}\right)\end{array}$ & $\begin{array}{l}\text { Peak } \\
\text { width } \\
\left(\mathrm{cm}^{-1}\right)\end{array}$ & Area $(\%)$ & $\begin{array}{c}\text { Peak } \\
\text { position } \\
\left(\mathrm{cm}^{-1}\right)\end{array}$ & $\begin{array}{l}\text { Peak } \\
\text { width } \\
\left(\mathrm{cm}^{-1}\right)\end{array}$ & Area $(\%)$ & $\begin{array}{c}\text { Peak } \\
\text { position } \\
\left(\mathrm{cm}^{-1}\right)\end{array}$ & $\begin{array}{l}\text { Peak } \\
\text { width } \\
\left(\mathrm{cm}^{-1}\right)\end{array}$ & Area (\%) \\
\hline Pk 1 & $s p^{3}-\mathrm{CH}_{2}(\mathrm{~s})$-poly & 2850 & 10 & 0.7 & 2847 & 15 & 4 & 2848 & 10 & 16 \\
\hline $\mathrm{Pk} 2$ & $s p^{3}-\mathrm{CH}_{2}(\mathrm{~s})$-amor & 2850 & 78 & $13 \cdot 3$ & 2850 & 81 & 13 & - & - & - \\
\hline Pk 3 & $s p^{3}-\mathrm{CH}_{3}(\mathrm{~s})$ & 2871 & 44 & $9 \cdot 7$ & 2870 & 34 & 5 & 2862 & 78 & 26 \\
\hline Pk 4 & $s p^{3}-\mathrm{CH}$ & 2915 & 6 & $0 \cdot 5$ & 2917 & 12 & $2 \cdot 5$ & 2917 & 11 & 14 \\
\hline Pk 5 & $s p^{3}-\mathrm{CH}_{2}$ (a) & 2918 & 57 & 30 & 2913 & 62 & 34 & 2915 & 40 & 39 \\
\hline Pk 6 & $s p^{3}-\mathrm{CH}_{3}(\mathrm{a})$ & 2961 & 67 & 18 & 2963 & 60 & $14 \cdot 5$ & 2957 & 11 & 3 \\
\hline Pk 7 & $s p^{2}-\mathrm{CH}(\mathrm{o})$ & 3005 & 124 & $27 \cdot 0$ & 3006 & 123 & 28 & - & - & - \\
\hline \multicolumn{2}{|c|}{ Average carbon coordination no. } & 3.698 & & & $3 \cdot 76$ & & & $3 \cdot 92$ & & \\
\hline
\end{tabular}

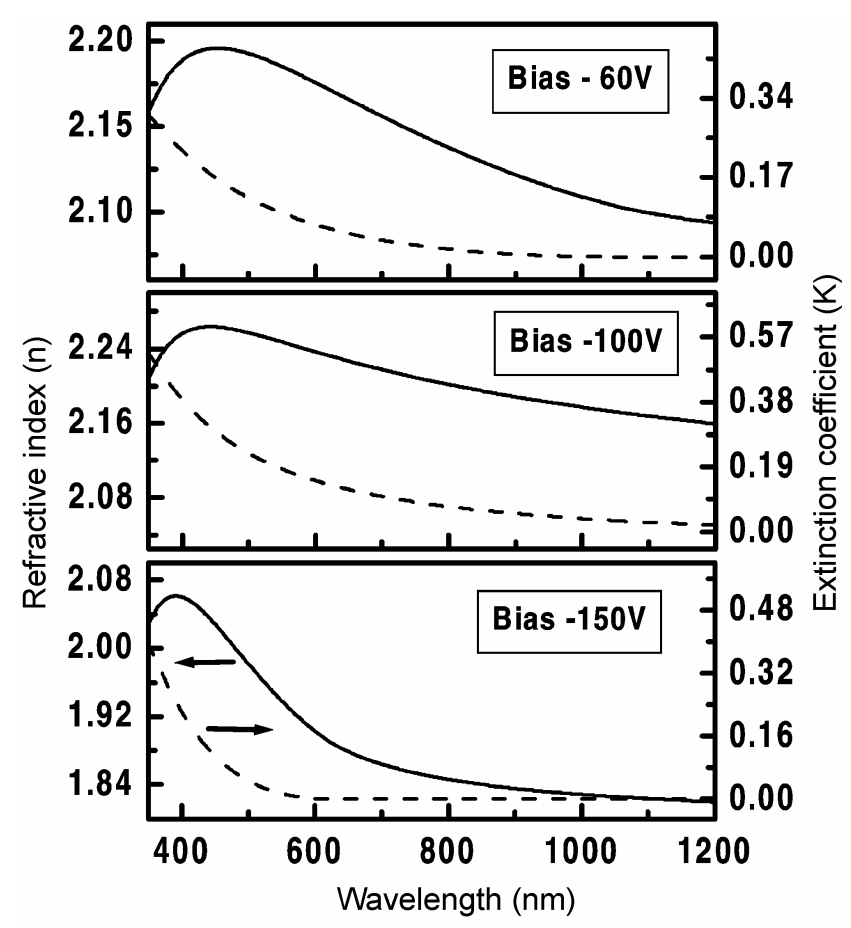

Figure 5. Variation of refractive index $(n)$ and extinction coefficient $(k)$ with wavelength for DLC films deposited at $-60 \mathrm{~V},-100 \mathrm{~V}$ and $-150 \mathrm{~V}$ bias.

shift in the maximum refractive index peak at different excitation wavelengths in the range $410-500 \mathrm{~nm}$. It is well known that the refractive index of the film is dependent on the density $\left(s p^{3} / s p^{2}\right.$ fraction of carbon bonding in the film). The variation in the shift of the maximum of the refractive index peak can, therefore, be associated with the varying ratio of carbon bonding $\left(s p^{3} / s p^{2}\right.$ fraction) in the film due to variation in the applied bias voltage.

The infrared spectra of DLC films deposited at different bias voltages $(-60 \mathrm{~V},-100 \mathrm{~V}$ and $-150 \mathrm{~V})$ are shown in figures $6 \mathrm{a}-\mathrm{c}$. Some sharp IR absorption bands in addition to the broad band that appear in the range 2800$3100 \mathrm{~cm}^{-1}$ are observed. These bands correspond to the different $\mathrm{C}-\mathrm{H}$ vibrations corresponding to the $s p^{3}$ and $s p^{2}$ clusters present in the films (Dischler et al 1983). While the spectra for the film deposited at $-60 \mathrm{~V}$ and $-100 \mathrm{~V}$ have been deconvoluted into seven Gaussian peaks, the spectra for film deposited at $-150 \mathrm{~V}$ have been deconvoluted into five Gaussian peaks. The assignment of these peaks marked pk 1 through pk7 is given in table 1 . The bands at $2870 \mathrm{~cm}^{-1}$ and $2961 \mathrm{~cm}^{-1}$ are due to symmetric and asymmetric vibrations of $s p^{3}-\mathrm{CH}_{3}$, while bands at $2850 \mathrm{~cm}^{-1}$ and $2920 \mathrm{~cm}^{-1}$ are due to symmetric and asymmetric vibrations of $s p^{3}-\mathrm{CH}_{2}$. In fact, the $s p^{3}-\mathrm{CH}$ also has its vibrational frequency in its close vicinity. Thus, a combined band due to asymmetric vibrations of $s p^{3}-\mathrm{CH}_{2}$ and $s p^{3}-$ $\mathrm{CH}$ appear in the range $2915-2925 \mathrm{~cm}^{-1}$. The bands corresponding to the $s p^{2}-\mathrm{CH}$ (olefinic) appear at $3000 \mathrm{~cm}^{-1}$. At a bias voltage of $-60 \mathrm{~V}$ there appears two peaks at $2850 \mathrm{~cm}^{-1}$, one sharp peak having a width of $\sim 10 \mathrm{~cm}^{-1}$ due to the symmetric vibrations of $s p^{3}-\mathrm{CH}_{2}$ and second broad peak having a width of $\sim 78 \mathrm{~cm}^{-1}$. Similarly one sharp and other broad band also appear at $\sim 2915 \mathrm{~cm}^{-1}$. Peak at $2870 \mathrm{~cm}^{-1}$ due to $s p^{3}-\mathrm{CH}_{3}$ (sym) which is found for films deposited at $-60 \mathrm{~V}$ and $-100 \mathrm{~V}$ bias, is absent for the film deposited at $-150 \mathrm{~V}$ substrate bias. In addition, the peak at $\sim 3005 \mathrm{~cm}^{-1}$, related to $s p^{2}-\mathrm{CH}$, is also absent in case of film deposited at $-150 \mathrm{~V}$ bias. The intensity of the sharp peaks is quite low for film deposited at $-60 \mathrm{~V}$, which develops in case of film deposited at $-100 \mathrm{~V}$ and become dominant at $-150 \mathrm{~V}$ bias value. To the best of our understanding, it appears that some polymeric component having sharp bands along with the diamond like carbon is present in the coatings. The polymeric component is increasing with increase in the substrate bias voltage, attaining a maximum at $-150 \mathrm{~V}$. In general, sharp IR bands are observed in case of soft-polymeric DLC films. However, the deposited films are not soft. The average carbon coordination number is determined from the fraction of $s p^{3}$ and $s p^{2}$ bonded carbon obtained from the $\mathrm{C}-\mathrm{H}$ absorption spectra of DLC films (Dischler et al 1983). The DLC film deposited at $-150 \mathrm{~V}$ bias is found to have higher carbon coordination number as compared to the films 
Table 2. Peak fitting details of Raman spectra.

\begin{tabular}{|c|c|c|c|c|c|}
\hline \multirow{2}{*}{$\begin{array}{l}\text { Substrate bias } \\
\text { voltage }(\mathrm{V})\end{array}$} & \multicolumn{2}{|c|}{ D peak } & \multicolumn{2}{|c|}{ G peak } & \multirow{2}{*}{$\begin{array}{c}I_{\mathrm{D}} / I_{\mathrm{G}} \\
\text { (Integrated } \\
\text { intensity ratio) }\end{array}$} \\
\hline & Position $\left(\mathrm{cm}^{-1}\right)$ & Width $\left(\mathrm{cm}^{-1}\right)$ & Position $\left(\mathrm{cm}^{-1}\right)$ & Width $\left(\mathrm{cm}^{-1}\right)$ & \\
\hline-60 & $1326 \cdot 85$ & $230 \cdot 98$ & 1535.46 & 151.89 & 0.67 \\
\hline-100 & $1327 \cdot 13$ & $219 \cdot 54$ & $1536 \cdot 1$ & $153 \cdot 17$ & $0 \cdot 60$ \\
\hline-150 & $1375 \cdot 0$ & $210 \cdot 85$ & $1587 \cdot 0$ & $104 \cdot 11$ & $1 \cdot 52$ \\
\hline
\end{tabular}
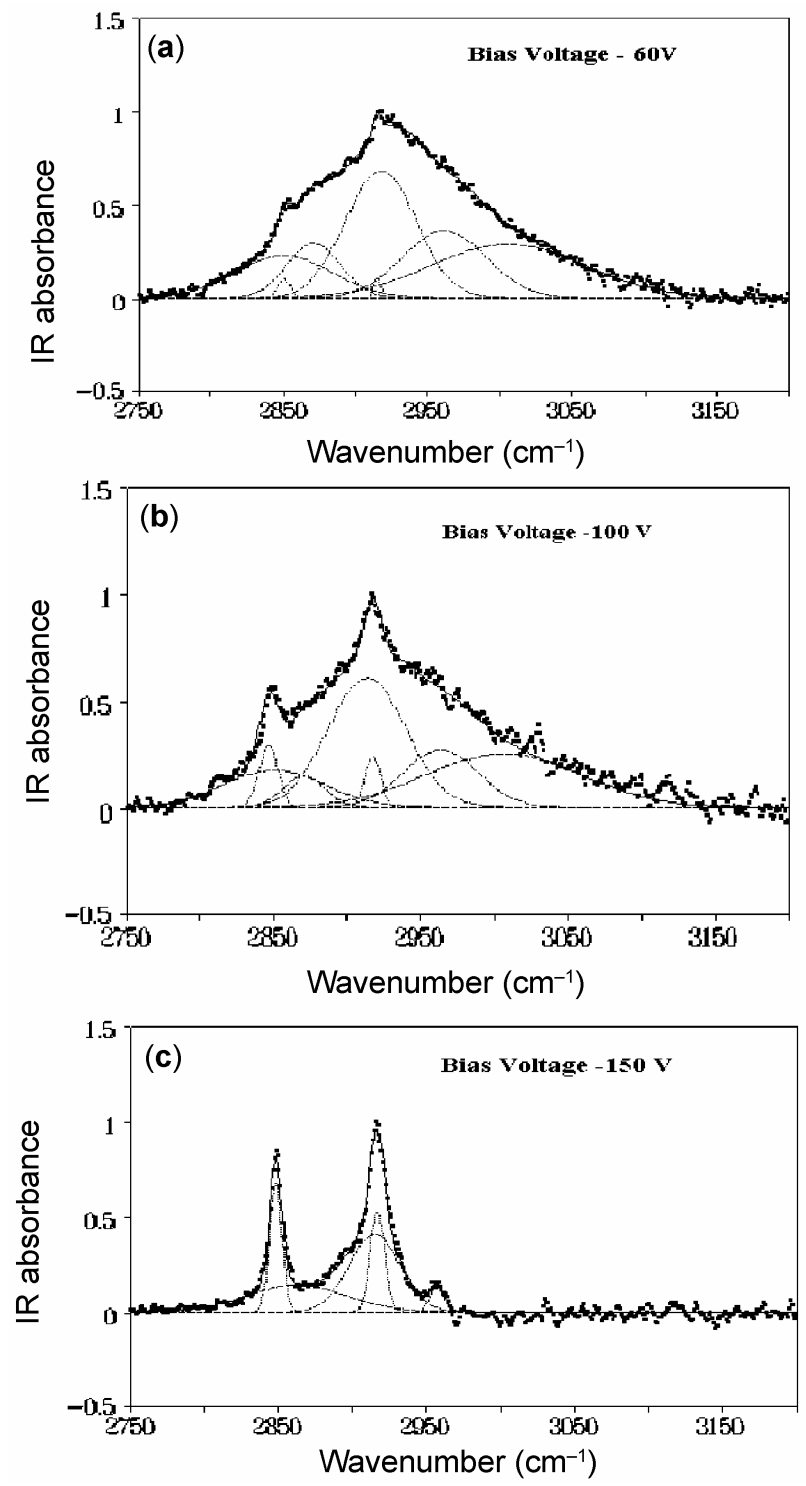

Figure 6. IR absorption spectra of DLC films deposited at (a) $-60 \mathrm{~V}$ bias, $(\mathbf{b})-100 \mathrm{~V}$ bias and $(\mathbf{c})-150 \mathrm{~V}$ bias

deposited at $-60 \mathrm{~V}$ and $-100 \mathrm{~V}$ bias, which indicates that the $s p^{3}$ bonded carbon content in this film should be high (in the absence of polymer component) and in that case this film should have higher hardness as compared to the other films. However, hardness measurements on this film show low hardness value as compared to the film deposited at $-100 \mathrm{~V}$ bias. It can, therefore, be inferred from the IR spectra that the polymeric component in the deposited films is increasing with the bias voltage, which leads to an increase in carbon coordination number.

Raman spectra of the films deposited at different substrate bias voltages $(-60 \mathrm{~V},-100 \mathrm{~V}$ and $-150 \mathrm{~V})$ are shown in figure 7 . The as recorded spectra showed a background signal along with the characteristic Raman features of DLC. Fitting these spectra with a third degree polynomial eliminated background signal. A nearly flat baseline obtained for the corrected spectra indicates a proper background subtraction. Later these spectra were fitted to a sum of two Gaussian peaks, one for D and other for Gband, characteristic of $s p^{2}$ bonded carbon clusters. The variation of $\mathrm{D}$ and $\mathrm{G}$-band positions along with their peak width and $I_{\mathrm{D}} / I_{\mathrm{G}}$ (integrated intensity ratio) is listed in table 2. Also given in this table is the $I_{\mathrm{D}} / I_{\mathrm{G}}$ (integrated intensity ratio) for the $\mathrm{D}$ and G-bands. D-band is found at $\sim 1327 \mathrm{~cm}^{-1}$ in case of films deposited at $-60 \mathrm{~V}$ and $-100 \mathrm{~V}$ bias voltages. This is blue shifted by considerable amount, $\sim 48 \mathrm{~cm}^{-1}$, in case of film deposited at $-150 \mathrm{~V}$ bias. The G-band is similarly found to be at $\sim 1536 \mathrm{~cm}^{-1}$ for film deposited at $-60 \mathrm{~V}$ and $-100 \mathrm{~V}$ bias levels, while it is again shifted by considerable amount, $\sim 51 \mathrm{~cm}^{-1}$, for film deposited at $-150 \mathrm{~V}$ bias. Wide variation in the positions of the $D$ and $G$ bands is found in the literature (D band: $1280-1400 \mathrm{~cm}^{-1}$ and $\mathrm{G}$ band: $1510-1630 \mathrm{~cm}^{-1}$ ), depending upon the microstructure of the aromatic clusters (Schwan et al 1996). Besides the changes in the position of the $D$ and $G$ bands, it is seen that the width of the $\mathrm{D}$ and $\mathrm{G}$ band in case of film deposited at $-150 \mathrm{~V}$ bias is also changing. The width of D-band is $\sim 230 \mathrm{~cm}^{-1}$ and $219 \mathrm{~cm}^{-1}$ for films deposited at $-60 \mathrm{~V}$ and $-100 \mathrm{~V}$ bias, which decreases to $\sim 211 \mathrm{~cm}^{-1}$ for film deposited at $-150 \mathrm{~V} \mathrm{sub-}$ strate bias. Width of the G-band for film deposited at $-150 \mathrm{~V}$ substrate bias is lower by $\sim 49 \mathrm{~cm}^{-1}$ as compared to its value for films deposited at $-60 \mathrm{~V}$ and $-100 \mathrm{~V}$ bias. The $I_{\mathrm{D}} / I_{\mathrm{G}}$ ratio for deposited films is also found to vary with bias, being $0.67,0.60$ and 1.52 for depositions carried out with substrate bias values of $-60 \mathrm{~V},-100 \mathrm{~V}$ and $-150 \mathrm{~V}$, respectively. The ratio $I_{\mathrm{D}} / I_{\mathrm{G}}$ is closely related to size of $s p^{2}$ clusters formed during the film growth and high concentration of $s p^{2}$ sites gives a large value of $I_{\mathrm{D}} / I_{\mathrm{G}}$ (Ferrari and Robertson 2000). It can be seen that the $I_{\mathrm{D}} / I_{\mathrm{G}}$ initially decreases with increasing bias voltage and then increases. For the film deposited at a bias of $-100 \mathrm{~V}$, the 


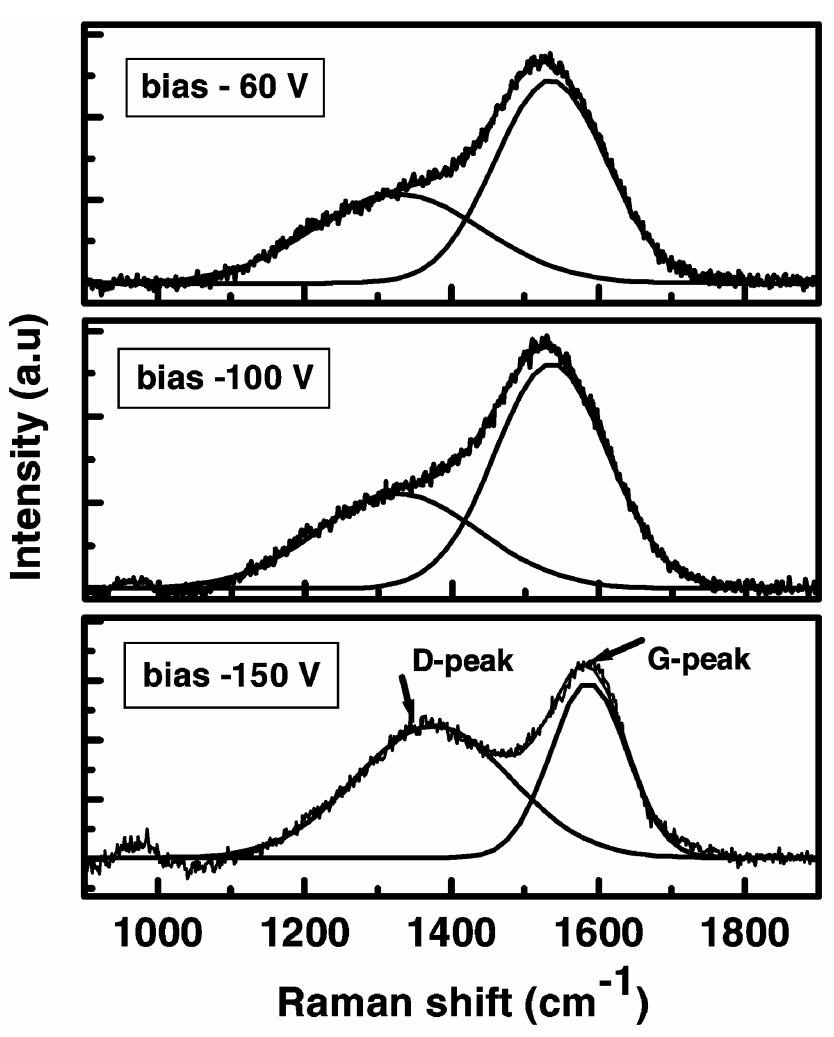

Figure 7. Raman spectra of DLC films (with Gaussian fit of $\mathrm{D}$ and $\mathrm{G}$ peaks) deposited at $-60 \mathrm{~V},-100 \mathrm{~V}$ and $-150 \mathrm{~V}$ bias.

width of $\mathrm{G}$ peak is high and $I_{\mathrm{D}} / I_{\mathrm{G}}$ is low. This suggests that the size of $s p^{2}$ bonded clusters in DLC film deposited at $-100 \mathrm{~V}$ bias is less as compared to the films deposited at $-60 \mathrm{~V}$ and $-150 \mathrm{~V}$ bias. The shift in the positions of $\mathrm{D}$ and $\mathrm{G}$ peak for film deposited at $-100 \mathrm{~V}$ bias is towards lower wave number. This coupled with decrease in $I_{\mathrm{D}} / I_{\mathrm{G}}$ is strongly indicative of an increase in the ratio of $s p^{3}$ to $s p^{2}$ bonded carbon configuration (Ferrari and Robertson 2000). Another measure of disorder is the width of Gpeak, which is related to distortions within each $s p^{2}$ cluster and is proportional to the stress and $s p^{3}$ fraction in the DLC films (Robertson 2003). The maximum in the G-peak width observed in case of film deposited at $-100 \mathrm{~V}$ bias correlates well with high hardness of the film.

The optical bandgap of these DLC films measured by ellipsometry shows a decrease with the increasing bias (from $-60 \mathrm{~V}$ to $-100 \mathrm{~V}$ ). The bandgap was $1.16 \mathrm{eV}$ and $0.82 \mathrm{eV}$, respectively for films deposited at $-60 \mathrm{~V}$ and $-100 \mathrm{~V}$ bias. This can be explained on the basis of the fact that optical bandgap is correlated with hydrogen content in the film, with increasing bias voltage the hydrogen content decreases up to certain bias value $(-100 \mathrm{~V})$ and so does optical bandgap. It is also possible that increasing substrate bias leads to higher ion bombardment of the deposited film that enhances the damage in the film, thus introducing more gap states that decrease the optical bandgap (Silva 1996). For the film deposited at $-150 \mathrm{~V}$ bias, the bandgap is increased to $1.98 \mathrm{eV}$. This increase in the bandgap may be due to the deposition of more polymeric component in the film.

\section{Conclusions}

Hard diamond like carbon films have been deposited by microwave ECR plasma CVD using plasma of methane and argon gases. Systematic investigations reported here indicate that the optical, mechanical properties and bonding characteristics of DLC films are strongly dependent on the substrate bias during deposition. The characterization results show that for the DLC film deposited at a substrate bias of $-100 \mathrm{~V}$, both hardness and refractive index reach maximum values. The extinction coefficient for all films has a value approaching zero beyond $800 \mathrm{~nm}$ indicating that these films are transparent beyond $800 \mathrm{~nm}$. The investigations reported here show the importance of the substrate bias in tuning the properties of the films.

\section{Acknowledgement}

(SBS) and (RMD) would like to acknowledge the Department of Atomic Energy, Government of India, for awarding Research Fellowships to them during the course of the work reported here.

\section{References}

Cicala G, Bruno P, Losacco A M and Mattei G 2004 Surf. Coat. Technol. 180-181 222

Dischler B, Bubenzer A and Koidl P 1983 Solid State Commun. 48105

Ferrari A C and Robertson J 2000 Phys. Rev. B61 14095

Groning O, Kuttel O M, Groning P and Schlapbach L 1997 Appl. Surf. Sci. 111135

Grill A 1993 Cold plasma in materials fabrication (New York: IEEE)

Kautek W, Pentzien S, Conradi A, Kruger J and Brzezinka K 1996 Appl. Surf. Sci. 106158

Lossy R, Pappas D L, Roy R A, Doyle J P and Cuomo J J 1995 J. Appl. Phys. 774750

Matsuo S and Kiuchi M 1983 Jpn. J. Appl. Phys. 22 L210

Musil J 1996 Vacuum 47145

Oliver W C and Pharr G M 1992 J. Mater. Res. 71564

Robertson J 2003 Semicond. Sci. Technol. 18 S12

Sanchez N A, Rincon C, Zambrano G, Galindo H and Prieto P 2000 Thin Solid Films 373247

Sarangi D, Panwar O S, Kumar S and Bhattacharyya R $2000 \mathrm{~J}$. Vac. Sci. Technol. A18 2302

Schwan J, Ulrich S, Batori V, Ehrhardt H and Silva S R P 1996 J. Appl. Phys. 80440

Silva S R P, Robertson J, Rusuli, Amaratunga G A J and Schwan J 1996 Philos. Mag. B74 369 